\title{
ESTÁDIOS DE MATURAÇÃo E VARIAÇÃO DA TEMPERATURA DE ARMAZENAMENTO NA QUALIDADE PÓS-COLHEITA DE AMEIXAS CV. AMARELINHA ${ }^{1}$
}

\author{
MARCELO BARBOSA MALGARIM르, FERNANDO RUFINO FLORES CANTILLANO ${ }^{3}$, \\ ROSA DE OLIVEIRA TREPTOW ${ }^{4}$, EDSON LUIS DE SOUZA ${ }^{5}$, ENILTON FICK COUTINHO ${ }^{2}$
}

\begin{abstract}
RESUMO - Ameixas, de modo geral, têm curto período de conservação pós-colheita, fazendo-se necessário otimizar as condições de colheita e de armazenamento. O trabalho objetivou avaliar o efeito do estádio de maturação e da variação de temperatura durante o armazenamento refrigerado na qualidade pós-colheita de ameixas cv. Amarelinha. As frutas foram selecionadas em três estádios de maturação e submetidas aos tratamentos: T1) 30 dias a $\left.0^{\circ} \mathrm{C} ; \mathrm{T} 2\right) 10 \operatorname{dias}$ a $0^{\circ} \mathrm{C}+5 \operatorname{dias}$ a $7^{\circ} \mathrm{C}+15 \operatorname{dias}$ a $\left.0^{\circ} \mathrm{C} ; \mathrm{T} 3\right) 10 \operatorname{dias}$ a $0^{\circ} \mathrm{C}+10$ dias a $7^{\circ} \mathrm{C}+10$ dias a $\left.0^{\circ} \mathrm{C} ; \mathrm{T} 4\right) 5$ dias a $0^{\circ} \mathrm{C}+5$ dias a $7^{\circ} \mathrm{C}+20$ dias a $0^{\circ} \mathrm{C}$; T5) 5 dias a $0^{\circ} \mathrm{C}+10$ dias a $7^{\circ} \mathrm{C}+15$ dias a $0^{\circ} \mathrm{C}$. A UR foi de 90 a $95 \%$ para todos os tratamentos. Após a retirada das frutas das câmaras frias mais três dias à temperatura de $20 \pm 1^{\circ} \mathrm{C}$, para simular a comercialização, avaliou-se a perda de peso, cor, firmeza de polpa, pH, sólidos solúveis totais (SST), acidez total titulável (ATT), relação SST/ATT, incidência de podridões e escurecimento interno e características sensoriais. Verificou-se que alternâncias nas temperaturas durante o armazenamento refrigerado reduzem o período de conservação de ameixas cv. Amarelinha; quando colhidas nos estádios de maturação verde e meio-maduro, podem ser armazenadas até 30 dias a $0^{\circ} \mathrm{C}$ e UR de $90-95 \%$.
\end{abstract}

Termos de Indexação: Prunus salicina, colheita, refrigeração, análise sensorial.

\section{STAGE OF MATURATION AND TEMPERATURE VARIATION DURING THE STORAGE ON POSTHARVEST QUALITY OF PLUMS CV. AMARELINHA}

\begin{abstract}
Plums quickly lose the fruit quality, during postharvest which makes imperative to optimize harvest and storage conditions. This work, had the objective to evaluate the effects of stages of maturation and temperature fluctuation on the postharvest quality of cold stored plums, 'Amarelinha'. Fruits were selected at 3 stages of maturation and stored using the following treatments: T1) 30 days at $0^{\circ} \mathrm{C}$; T2) 10 days at $0^{\circ} \mathrm{C}+5$ days at $7^{\circ} \mathrm{C}+15$ days at $0^{\circ} \mathrm{C}$; T3) 10 days at $0^{\circ} \mathrm{C}+10$ days at $7^{\circ} \mathrm{C}+10$ days at $0^{\circ} \mathrm{C}$; T4) 5 days at $0^{\circ} \mathrm{C}+5$ days at $7^{\circ} \mathrm{C}+20$ days at $0^{\circ} \mathrm{C}$; $\left.\mathrm{T} 5\right) 5$ days at $0^{\circ} \mathrm{C}+10$ days at $7^{\circ} \mathrm{C}+150^{\circ} \mathrm{C}$. The RH was $90-95 \%$. Three days after the fruits were taken out of the cold storage, they were evaluated for weight loss, color, firmness, $\mathrm{pH}$, total soluble solids (TSS), total titratable acidity (TTA), TSS/TTA ratio, incidence of rotten and/or internal browning and sensorial characteristics. The results show that temperature fluctuation reduces the cold storage preservation capacity of plums 'Amarelinha'; harvested at green and mid maturity stages, can be stored up to 30 days at $0^{\circ} \mathrm{C}$ and $90-95 \% \mathrm{RH}$.
\end{abstract}

Index Terms: Prunus salicina, crop, refrigeration, sensorial analysis.

\section{INTRODUÇÃO}

O interesse pela pós-colheita de frutas tem aumentado nos últimos anos no Brasil, em virtude de grandes safras, do aumento do consumo, da necessidade de um abastecimento permanente do mercado com frutas frescas e do incremento no volume de exportações (Beling, 2004).

A cultura da ameixeira encontra-se em expansão no Brasil. As perdas durante a colheita e pós-colheita de frutas no Brasil são da ordem de 30 a $40 \%$. Grande parte deste elevado percentual se deve ao manejo deficiente na colheita e pós-colheita (Lombadi, 2003).

$\mathrm{O}$ consumidor tem se tornado cada vez mais exigente quanto à qualidade do produto final. Isso tem motivado a preocupação no que se refere à preservação da qualidade da fruta, visando ao prolongamento, no período de comercialização, e à maior resistência ao ataque de doenças e à ocorrência de distúrbios fisiológicos.

Um dos grandes desafios durante o armazenamento é reduzir ao máximo as perdas; para se alcançar esse objetivo, é necessário empregar técnicas adequadas, de tal forma que o produto chegue ao consumidor com a qualidade desejável. Como a atividade metabólica continua na pós-colheita, as frutas necessitam reduzir essa atividade para proporcionar maior tempo de comercialização (Chitarra \& Chitarra, 1990). É importante observar e manter uma constante qualidade de frutas armazenadas, adotando-se técnicas especiais e evitando-se injúrias tanto mecânicas como fisiológicas.

As operações tecnológicas realizadas em pós-colheita, se bem conduzidas, permitirão, portanto, não somente minimizar as perdas, mas também manter a qualidade das frutas por um maior período. As ameixas têm, normalmente, um limitado período pós-colheita, devido a fatores como a elevada desidratação e a perda de firmeza da polpa, sensibilidade a danos mecânicos durante a colheita e manuseio, incidência de fungos durante o armazenamento e distúrbios fisiológicos, originados pelo frio e/ou grau de maturação inadequado (Kluge et al., 1997).

O distúrbio fisiológico mais importante em ameixas é o colapso da polpa "Internal Breakdown", originado por danos de frio durante o resfriamento prolongado, sendo essa desordem caracterizada pelo escurecimento do mesocarpo, tornando-as com aparência e sabor desagradáveis (Kluge et al., 1997).

O presente trabalho foi conduzido para avaliar o efeito do estádio de maturação e da alternância de temperatura, durante o armazenamento refrigerado, na qualidade pós-colheita de ameixas (Prunus salicina, Lindl), cv. Amarelinha.

\section{MATERIALEMÉTODOS}

O experimento foi conduzido em câmaras frigoríficas e nos laboratórios de Pós-colheita e de Tecnologia de Alimentos do Centro de Pesquisa Agropecuária de Clima Temperado, EMBRAPA/CPACT, em Pelotas-RS.

Foram utilizadas ameixas (Prunus salicina, Lindl.) cv. Amarelinha, provenientes de pomar localizado na Embrapa Clima Temperado, Pelotas-RS. As frutas foram colhidas manualmente e aleatoriamente nas diferentes posições e orientações da planta, em 2 de janeiro de 2002, descartando-se as frutas com defeitos visuais, injúrias

\footnotetext{
${ }^{1}$ (Trabalho 110/2004). Recebido: 21/09/2004. Aceito para publicação: 09/03/2005.

${ }^{2}$ Eng. Agr., MSc., Doutorando em Fruticultura de Clima Temperado UFPeI, malgarim@ ufpel.tche.br - Fone: 0532758189

${ }^{3}$ Eng. Agr., Dr., Pesquisador, EMBRAPA-CPACT, fcantill@ cpact.embrapa.br - Fone: 0532758185

${ }^{4}$ Economista Doméstica, MSc., UFPel, Cx. P. 394, CEP 96001-970, Pelotas-RS.

${ }^{5}$ Eng. Agr., MSc., Ciência e Tecnologia Agroindustrial, UFPel, Pelotas-RS.
} 
TABELA 1 - Caracterização físico-química na colheita de ameixas cv. Amarelinha

\begin{tabular}{|c|c|c|c|}
\hline \multirow{2}{*}{ Variáveis } & \multicolumn{3}{|c|}{ Estádios de maturação } \\
\hline & Verde (M1) & Meio-maduro (M2) & Maduro (M3) \\
\hline Cor (Ângulo Hue) & 99,22 & 96,28 & 92,82 \\
\hline Firmeza de polpa (Newton) & 67,75 & 63,98 & 63,71 \\
\hline Sólidos solúveis totais - SST ( ${ }^{\circ}$ Brix) & 13,10 & 13,30 & 13,63 \\
\hline Acidez total titulável - ATT (\% ac. málico) & 1,02 & 0,96 & 0,88 \\
\hline Relação SST/ATT & 12,80 & 13,83 & 15,38 \\
\hline $\mathrm{pH}$ & 2,87 & 2,92 & 2,99 \\
\hline Peso médio $(\mathrm{g})$ & 59,03 & 64,56 & 61,89 \\
\hline
\end{tabular}

Colheita em 02-01-2002.

mecânicas, ataque fúngico e/ou de insetos. Avaliaram-se também as características físicas, químicas e sensoriais.

Na seleção das ameixas, em relação ao estádio de maturação, adotou-se o critério de cor da epiderme característica da cultivar em três estádios de maturação: estádio de maturação verde (M1) até $25 \%$ de cor característica; estádio de maturação meio-maduro (M2) de 25 a $50 \%$ de cor característica, e estádio de maturação maduro (M3) mais que 50\% de cor característica.

$\mathrm{O}$ armazenamento refrigerado foi realizado em duas câmaras frigoríficas, uma mantida a $0^{\circ} \mathrm{C}$ e outra a $7^{\circ} \mathrm{C}$. As temperaturas tiveram variação máxima de $\pm 0,5^{\circ} \mathrm{C}$, e a umidade relativa variou de 90 a $95 \%$.

Durante o armazenamento das ameixas, os tratamentos (T) tiveram as seguintes variações de temperaturas: T1) 30 dias a $0^{\circ} \mathrm{C}$ (testemunha); T2) dez dias a $0^{\circ} \mathrm{C}+$ cinco dias a $7^{\circ} \mathrm{C}+15$ dias a $0^{\circ} \mathrm{C} ; \mathrm{T} 3$ ) dez dias a $0^{\circ} \mathrm{C}+\operatorname{dez} \operatorname{dias}$ a $7^{\circ} \mathrm{C}+\operatorname{dez} \operatorname{dias}$ a $0^{\circ} \mathrm{C}$; T4) cinco dias a $0^{\circ} \mathrm{C}+$ cinco dias a $7^{\circ} \mathrm{C}+20$ dias a $0^{\circ} \mathrm{C}$; e T5) cinco dias a $0^{\circ} \mathrm{C}+\operatorname{dez} \operatorname{dias}$ a $7^{\circ} \mathrm{C}+$ 15 dias a $0^{\circ} \mathrm{C}$.

Após trinta dias de armazenamento, as frutas foram retiradas das respectivas frigorificações e colocadas três dias em câmara com temperatura controlada de $20 \pm 1^{\circ} \mathrm{C}$ e umidade relativa de 75 a $80 \%$, simulando um período de comercialização.

Na colheita e após o período de armazenamento e simulação de comercialização, foram avaliadas as seguintes variáveis: perda de peso calculada em porcentagem (\%) a partir das diferenças de peso das unidades experimentais observadas entre o momento da instalação e das avaliações de controle; cor de superfície e de fundo da epiderme medida em colorímetro Minolta CR-300, com fonte de luz D 65, com 8mm de abertura, com duas leituras em lados opostos na região equatorial das ameixas. No padrão C.I.E. $L^{*} a^{*} b^{*}$, a coordenada $L^{*}$ expressa o grau de luminosidade da cor medida. A coordenada $a^{*}$ expressa o grau de variação entre o vermelho e o verde. A coordenada $b^{*}$ expressa o grau de variação entre o azul e $o$ amarelo. Os valores $a^{*}, b^{*}$ foram usados para calcular o ângulo Hue ou matiz $\left({ }^{\circ} h^{*}=\operatorname{tang}^{-1} b^{*} \cdot a^{*-1}\right)$; firmeza de polpa (FP) medida com penetrômetro manual McCornick FT 327 com ponteira de $5 / 16$ polegadas de diâmetro, após a remoção localizada da epiderme, realizando-se duas leituras em lados opostos da secção equatorial das ameixas, expressas em Newton $(\mathrm{N})$; $\mathrm{pH}$ determinado com peagâmetro Micronal modelo B-271, utilizando-se de uma amostra de suco puro de cada repetição; sólidos solúveis totais (SST) por refratometria, sendo realizada com um refratômetro de mesa Shimadzu, com correção de temperatura para $20^{\circ} \mathrm{C}$, utilizando-se de uma gota de suco puro de cada repetição, expressando-se o resultado em ${ }^{\circ}$ Brix; acidez total titulável (ATT), com a diluição de $10 \mathrm{~mL}$ de suco puro em $90 \mathrm{~mL}$ de água destilada e titulação com uma solução de $\mathrm{NaOH} 0,1 \mathrm{~N}$, até $\mathrm{pH} 8,1$, expressando-se o resultado em \% de ácido málico, segundo a metodologia de Manzino et al. (1987); relação SST/ATT pelo quociente entre os dois constituintes; incidência de podridões, considerando-se podres as frutas com características típicas de ataque de patógenos, expressando em porcentagem de frutas podres; escurecimento interno determinado através de observação visual, considerando afetadas aquelas frutas com a polpa escurecida, sendo expresso em porcentagem de frutas com o sintoma característico.

A avaliação sensorial foi realizada por uma equipe treinada de dez julgadores. O método empregado foi o Descritivo, teste de avaliação de atributos, segundo Lawless \& Haymann (1998). Os dados foram coletados através de fichas individuais, utilizando escalas nãoestruturadas de $9 \mathrm{~cm}$, cujo extremo esquerdo corresponde à menor intensidade e o direito à maior intensidade dos atributos analisados. Os julgadores avaliaram as características de aparência, compreendendo os atributos de cor da epiderme, defeitos e desidratação; características de sabor: incluindo doçura, acidez, sabor característico, sabor estranho; características de textura: sendo avaliada a firmeza e a suculência. As avaliações foram realizadas em cabines individuais. As amostras foram cortadas em pedaços, com tamanho-padrão e colocadas em pratos brancos, codificados com três dígitos aleatórios. Também foram avaliadas a simulação da comercialização e a qualidade geral, representando a primeira a intenção de compra, levando-se em consideração as características de aparência, e a segunda, o conjunto de características de sabor e textura.

As avaliações das características de aparência foram realizadas em uma mesa central, no Laboratório de Avaliação Sensorial, com controle de iluminação, sendo as frutas colocadas em bandejas plásticas brancas e codificadas.

Para as análises físicas e químicas, o delineamento experimental utilizado foi o de blocos ao acaso, em fatorial de 3 estádios de maturação x 5 tratamentos. A unidade experimental foi composta de dez ameixas, com três repetições. Com os dados registrados, foi calculada a variância, sendo as médias comparadas pelo teste de DMS $(\mathrm{p} \leq 0,05)$. Na análise sensorial, o delineamento experimental foi o de blocos casualizados. Após a análise da variância, as médias foram comparadas pelo teste de Tukey $(\mathrm{p} \leq 0,05)$.

\section{RESULTADOSE DISCUSSÃO}

Na caracterização físico-química e sensorial realizada na colheita, as frutas tiveram diferentes características conforme o estádio de maturação. De modo geral, ameixas colhidas no estádio de maturação M3 tiveram características físico-químicas e sensoriais superiores e no estádio M1, características inferiores (Tabelas 1 e 2).

Após 30 dias de armazenamento refrigerado mais três dias de simulação de comercialização, ocorreu interação significativa na variável perda de peso entre os estádios de maturação e as diferentes variações de temperatura. As ameixas da cv. Amarelinha tiveram maiores perdas de peso nos tratamentos com variação de temperatura, com exceção do T5, e de modo geral, no estádio de maturação M1, ocorreram os maiores valores (Tabela 3). Isso indica que a fruta colhida no estádio de maturação meio-maduro e armazenada em temperatura baixa e constante tem menor perda de peso. A taxa respiratória das ameixas aumenta, à medida que se eleva a temperatura. Consequientemente, o emprego de baixa temperatura diminui, acentuadamente, os níveis de respiração, e seu efeito prolonga a manutenção das substâncias de reservas (Chitarra \& Chitarra, 1990). Segundo Kluge et al. (1999), a taxa de transpiração, normalmente, é maior em frutas colhidas verdes, se comparadas com frutas colhidas no estádio de maturação meio-maduro.

Analisando-se individualmente os fatores variações de temperatura e estádios de maturação, observou-se que ameixas colhidas no estádio de maturação M1 tiveram maior pigmentação verde, representada pelos maiores valores do ângulo Hue $\left({ }^{\circ} h\right)$, e as ameixas 
TABELA 2 - Caracterização sensorial na colheita de ameixas cv. Amarelinha (escala de $9 \mathrm{~cm}$ )

\begin{tabular}{lccc}
\hline \multirow{2}{*}{ Variáveis } & & Estádios de maturação & Maduro (M3) \\
\cline { 2 - 4 } Cor & Verde (M1) & Meio-maduro (M2) & 4,73 \\
Defeitos & 0,89 & 2,88 & 2,53 \\
Desidratação & 1,79 & 2,07 & 0,06 \\
Comercialização & 0,03 & 0,06 & 8,41 \\
Doçura & 1,66 & 4,71 & 4,21 \\
Acidez & 1,80 & 2,60 & 4,36 \\
Sabor & 7,40 & 5,95 & 6,87 \\
Sabor estranho & 3,95 & 4,94 & 0,16 \\
Firmeza & 0,06 & 0,14 & 5,42 \\
Suculência & 7,79 & 6,71 & 6,58 \\
Fibra & 5,09 & 5,86 & 0,05 \\
Qualidade geral & 0,13 & 0,06 & 7,47 \\
\hline Collat
\end{tabular}

Colheita em 02-01-2002.

colhidas no estádio de maturação M3 tiveram os menores valores, indicando maior pigmentação amarela e vermelha. Assim como após o armazenamento, as frutas submetidas aos tratamentos $\mathrm{T} 1, \mathrm{~T} 2 \mathrm{e} \mathrm{T} 4$ tiveram os maiores valores do ${ }^{\circ} \mathrm{h}$ (Tabela 3 ).

A menor evolução da cor ocorreu, provavelmente, devido à redução no avanço do processo de maturação nas frutas dos tratamentos T1, T2 e T4, gerado pelas baixas temperaturas, o que é desejável do ponto de vista comercial; entretanto, é necessário que as frutas tenham capacidade de amadurecer, normalmente, quando colocadas em condição ambiente. Nas frutas dos tratamentos T3 e T5, o avanço no processo de maturação ocorreu devido ao aumento da temperatura para $7^{\circ} \mathrm{C}$, durante o período de dez dias. Segundo Girardi et al. (2000), quando a cor passa de verde para amarela, ocorre a degradação da clorofila, que está associada à síntese de antocianinas, as quais são responsáveis pela cor de recobrimento ou de superfície.

Quanto à cor da epiderme de ameixas, é uma das características que o consumidor utiliza para avaliar sua qualidade e disposição de compra. Essa transformação, embora seja um processo subjetivo, mostrase confiável, na determinação do ponto de colheita (Kluge et al., 1999).

$\mathrm{Na}$ variável $\mathrm{pH}$, ocorreu interação significativa entre estádios de maturação e tratamentos. Os maiores valores ocorreram nas frutas no estádio de maturação M3, indicando menor acidez, e, de modo geral, as frutas dos tratamentos T2, T3 e T5 tiveram os maiores valores de $\mathrm{pH}$, indicando o maior avanço da maturação (Tabela 3). Helbig (1998),

TABELA 3 - Perda de Peso, pH, Sólidos Solúveis Totais (SST), Acidez Total Titulável (ATT), Relação SST/ATT e Cor nas diferentes variações de temperatura e estádios de maturação de ameixas cv. Amarelinha após 30 dias de armazenamento e 3 de simulação de comercialização

\begin{tabular}{|c|c|c|c|c|}
\hline \multirow{2}{*}{ Variáveis } & \multirow{2}{*}{ Tratamentos } & \multicolumn{3}{|c|}{ Estádios de Maturação } \\
\hline & & Verde (M1) & Meio-maduro (M2) & Maduro (M3) \\
\hline \multirow{5}{*}{ Perda de Peso (\%) } & T1 & $4,01 \mathrm{bA}$ & $3,97 \mathrm{abA}$ & $3,67 \mathrm{aA}$ \\
\hline & $\mathrm{T} 2$ & $4,81 \mathrm{abA}$ & 4,83 aA & 4,38 aA \\
\hline & T3 & $5,02 \mathrm{abA}$ & $4,03 \mathrm{abB}$ & $4,13 \mathrm{aAB}$ \\
\hline & $\mathrm{T} 4$ & 5,65 aA & $3,70 \mathrm{bB}$ & $4,35 \mathrm{aB}$ \\
\hline & T5 & $4,27 \mathrm{bA}$ & $4,98 \mathrm{aA}$ & $4,71 \mathrm{aA}$ \\
\hline \multirow{5}{*}{$\mathrm{pH}$} & $\mathrm{T} 1$ & $2,87 \mathrm{bB}$ & $2,90 \mathrm{bB}$ & $3,10 \mathrm{bA}$ \\
\hline & $\mathrm{T} 2$ & $3,01 \mathrm{aB}$ & $3,02 \mathrm{aB}$ & 3,17 aA \\
\hline & T3 & $3,05 \mathrm{aB}$ & $3,09 \mathrm{aB}$ & $3,21 \mathrm{aA}$ \\
\hline & $\mathrm{T} 4$ & $2,91 \mathrm{bB}$ & $2,98 \mathrm{abB}$ & $3,11 \mathrm{bA}$ \\
\hline & T5 & $3,01 \mathrm{aB}$ & $3,08 \mathrm{aB}$ & $3,14 \mathrm{abA}$ \\
\hline \multirow{5}{*}{$\begin{array}{c}\text { Sólidos Solúveis Totais - } \\
\text { SST ( }{ }^{\circ} \text { Brix) }\end{array}$} & T1 & $12,95 \mathrm{aB}$ & $13,42 \mathrm{aAB}$ & $14,28 \mathrm{aA}$ \\
\hline & $\mathrm{T} 2$ & $13,22 \mathrm{aB}$ & $13,48 \mathrm{aAB}$ & $13,95 \mathrm{aA}$ \\
\hline & $\mathrm{T} 3$ & $12,81 \mathrm{aB}$ & $13,21 \mathrm{aAB}$ & $13,55 \mathrm{aA}$ \\
\hline & $\mathrm{T} 4$ & $12,81 \mathrm{aB}$ & $13,48 \mathrm{aA}$ & $13,55 \mathrm{aA}$ \\
\hline & T5 & $13,01 \mathrm{aA}$ & $13,55 \mathrm{aA}$ & $13,48 \mathrm{aA}$ \\
\hline \multirow{5}{*}{$\begin{array}{c}\text { Acidez Total Titulável - } \\
\text { ATT } \\
\text { (\% de ácido málico })\end{array}$} & T1 & $1,04 \mathrm{aA}$ & $0,95 \mathrm{aA}$ & $0,71 \mathrm{aB}$ \\
\hline & $\mathrm{T} 2$ & $0,89 \mathrm{bA}$ & $0,76 \mathrm{bB}$ & $0,58 \mathrm{bC}$ \\
\hline & $\mathrm{T} 3$ & $0,69 \mathrm{cA}$ & $0,62 \mathrm{cAB}$ & $0,53 \mathrm{bB}$ \\
\hline & $\mathrm{T} 4$ & $0,93 \mathrm{bA}$ & $0,75 \mathrm{bB}$ & $0,64 \mathrm{abC}$ \\
\hline & T5 & $0,71 \mathrm{cA}$ & $0,65 \mathrm{bcA}$ & $0,55 \mathrm{bB}$ \\
\hline \multirow{5}{*}{ Relação SST/ATT } & $\mathrm{T} 1$ & $12,38 \mathrm{cC}$ & $14,03 \mathrm{cB}$ & $20,35 \mathrm{bA}$ \\
\hline & $\mathrm{T} 2$ & $14,85 \mathrm{bC}$ & $17,92 \mathrm{bB}$ & $24,08 \mathrm{aA}$ \\
\hline & $\mathrm{T} 3$ & $18,40 \mathrm{aC}$ & $21,22 \mathrm{aB}$ & $25,56 \mathrm{aA}$ \\
\hline & $\mathrm{T} 4$ & $13,75 \mathrm{bcC}$ & $18,01 \mathrm{bB}$ & $21,18 \mathrm{bA}$ \\
\hline & $\mathrm{T} 5$ & $18,17 \mathrm{aC}$ & $20,66 \mathrm{aB}$ & $24,55 \mathrm{aA}$ \\
\hline \multirow{5}{*}{ Cor (Ângulo Hue) } & $\mathrm{T} 1$ & $96,15 \mathrm{aA}$ & $93,10 \mathrm{aB}$ & $88,74 \mathrm{aC}$ \\
\hline & $\mathrm{T} 2$ & $94,24 \mathrm{abA}$ & $91,68 \mathrm{abB}$ & $87,38 \mathrm{abC}$ \\
\hline & $\mathrm{T} 3$ & $91,61 \mathrm{bA}$ & $88,78 \mathrm{bB}$ & $85,28 \mathrm{bC}$ \\
\hline & $\mathrm{T} 4$ & $96,36 \mathrm{aA}$ & $91,69 \mathrm{aB}$ & $89,32 \mathrm{aC}$ \\
\hline & T5 & $92,03 \mathrm{bA}$ & $90,00 \mathrm{bB}$ & $86,54 \mathrm{bC}$ \\
\hline
\end{tabular}

Médias seguidas da mesma letra maiúscula na linha ou mesma letra minúscula na coluna não diferem entre si, pelo teste de Tukey $(\mathrm{p}<0,05)$. T1 $=30$ dias a $0^{\circ} \mathrm{C} ; \mathrm{T} 2=$ 10 dias a $0^{\circ} \mathrm{C}+5 \operatorname{dias}$ a $7^{\circ} \mathrm{C}+15 \operatorname{dias}$ a $0^{\circ} \mathrm{C} ; \mathrm{T} 3=10 \operatorname{dias}$ a ${ }^{\circ} \mathrm{C}+10 \operatorname{dias}$ a $7^{\circ} \mathrm{C}+10$ dias a $0^{\circ} \mathrm{C} ; \mathrm{T} 4=5 \operatorname{dias}$ a $0^{\circ} \mathrm{C}+5 \operatorname{dias}$ a $7^{\circ} \mathrm{C}+20$ dias a $0^{\circ} \mathrm{C} ; \mathrm{T} 5=5$ dias a $0^{\circ} \mathrm{C}+$ 10 dias a $7^{\circ} \mathrm{C}+15$ dias a $0^{\circ} \mathrm{C}$. 
trabalhando com ameixas cv. Wade, verificou que o $\mathrm{pH}$ aumentou com o avanço da maturação ao longo do período de armazenamento. Segundo Cantillano \& Malgarim (2002), em ameixas cv. Amarelinha, o aumento do pH está relacionado com o avanço do estádio de maturação durante o armazenamento.

Na variável SST, não ocorreu interação entre as variações de temperatura e estádios de maturação. Também não foram determinadas diferenças significativas entre tratamentos. As frutas do estádio de maturação M1 tiveram os menores valores, e as do estádio M3 os maiores, sendo que os valores dos SSTs oscilaram entre 12,81 e 14,28 ${ }^{\circ}$ Brix (Tabela 3 ), indicando que, apesar de haver diferenças significativas entre as médias, a variação foi pequena. Resultados semelhantes foram encontrados por Kluge et al. (1999), cujos valores oscilaram entre 13,4 e $14,4^{\circ} \mathrm{Brix}$, respectivamente, nos estádios de maturação verde a maduro.

Os valores de acidez total titulável tiveram interação significativa entre os diferentes estádios de maturação e variações de temperatura. A acidez diminuiu com o avanço dos estádios de maturação. No tratamento $\mathrm{T} 1$, as frutas tiveram menor redução na acidez, provavelmente, devido à temperatura de armazenamento uniforme e constante. As frutas dos tratamentos T3 e T5 tiveram menor acidez, devido a serem submetidas à temperatura de $7^{\circ} \mathrm{C}$ por um período maior (Tabela 3).

O decréscimo na ATT ocorre devido ao metabolismo respiratório que continua ocorrendo após a colheita, fazendo com que substratos, dentre os quais os ácidos, sejam utilizados no ciclo de Krebs, como forma de geração de energia para a manutenção dos processos vitais das frutas (Chitarra \& Chitarra, 1990).

A relação SST/ATT foi significativamente menor nas frutas do estádio de maturação M1, o que pode ser explicado pelos maiores valores de ATT, enquanto comportamento inverso foi verificado nas ameixas do estádio de maturação M3, alcançando valores entre 20,35 e 25,56 (Tabela 3).

As frutas dos tratamentos T3 e T5 tiveram maior relação SST/ ATT devido ao maior avanço da maturação, causado pela temperatura de $7^{\circ} \mathrm{C}$ por um maior período (Tabela 3 ).

Segundo Chitarra \& Chitarra (1990), a relação SST/ATT é uma das melhores formas de avaliação do sabor, sendo mais representativa que a medição isolada de açúcares ou da acidez; entretanto, há necessidade de conhecer os teores de SST e ATT para ter-se uma idéia real do sabor.
Os valores da relação SST/ATT estão abaixo de 30, segundo Kluge \& Cantillano (1997), a relação SST/ATT superior a 30 indica a sobrematuração de ameixas da cultivar Amarelinha, a partir de quatro semanas de refrigeração a $0^{\circ} \mathrm{C}$.

$\mathrm{Na}$ variável firmeza de polpa, ocorreu interação significativa entre as variações de temperatura e estádios de maturação. As frutas colhidas no estádio de maturação M1 tiveram maior firmeza de polpa em todos os tratamentos, sendo o maior valor encontrado na interação estádio de maturação M1 e tratamento T1 (Figura 1). A diminuição da firmeza de polpa é normal, já que há relação direta entre a evolução da maturação e a perda de firmeza da polpa (Southy et al., 1990). A firmeza de polpa é influenciada pelas substâncias pécticas que compõem as paredes celulares, e, à medida que a fruta amadurece, essas substâncias são polimerizadas e ocorre o amaciamento da polpa (Kluge et al., 1997).

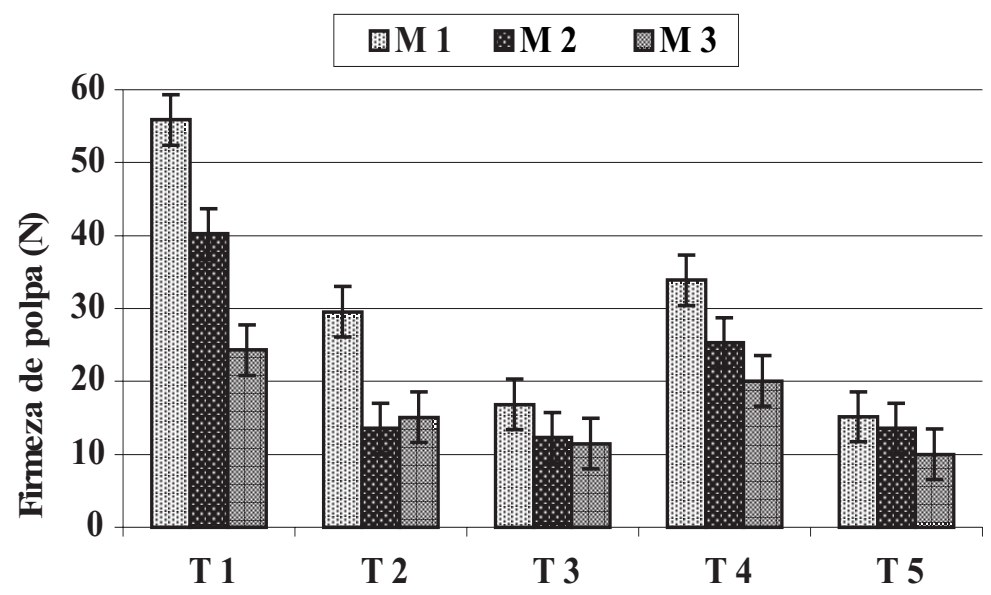

FIGURA 1 - Firmeza de polpa (N) nas diferentes variações de temperatura e estádios de maturação em ameixas cv. Amarelinha. T1= 30 dias a $0^{\circ} \mathrm{C} ; \mathrm{T} 2=10$ dias a $0^{\circ} \mathrm{C}+05$ dias a $7^{\circ} \mathrm{C}+15$ dias a $0^{\circ} \mathrm{C} ; \mathrm{T} 3=10$ dias a $0^{\circ} \mathrm{C}+10$ dias a $7^{\circ} \mathrm{C}+10$ dias a $0^{\circ} \mathrm{C} ; \mathrm{T} 4=$ 05 dias a $0^{\circ} \mathrm{C}+05$ dias a $7^{\circ} \mathrm{C}+20$ dias a $0^{\circ} \mathrm{C} ; \mathrm{T} 5=05$ dias a $0^{\circ} \mathrm{C}+10$ dias a $7^{\circ} \mathrm{C}+15$ dias a $0^{\circ} \mathrm{C}$. Estádios de maturação M1 (verde); M2 (meio-maduro) e M3 (maduro). Barra vertical: intervalo DMS $(\mathrm{p}<0,05)$.

TABELA 4 - Avaliação sensorial das características de aparência (escala de $9 \mathrm{~cm}$ ) nas diferentes variações de temperatura e estádios de maturação de ameixas cv. Amarelinha após 30 dias de armazenamento e 3 de simulação de comercialização.

\begin{tabular}{|c|c|c|c|c|}
\hline \multirow{2}{*}{$\begin{array}{c}\text { Características de } \\
\text { aparência }\end{array}$} & \multirow{2}{*}{ Tratamentos } & \multicolumn{3}{|c|}{ Estádios de Maturação } \\
\hline & & Verde (M1) & Meio-maduro (M2) & Maduro (M3) \\
\hline \multirow{5}{*}{ Cor } & T1 & $2,38 \mathrm{cC}$ & $3,75 \mathrm{cB}$ & $5,13 \mathrm{aA}$ \\
\hline & $\mathrm{T} 2$ & $4,08 \mathrm{bB}$ & $5,12 \mathrm{bB}$ & $6,36 \mathrm{abA}$ \\
\hline & $\mathrm{T} 3$ & $6,71 \mathrm{aB}$ & $6,75 \mathrm{aB}$ & $7,81 \mathrm{bA}$ \\
\hline & $\mathrm{T} 4$ & $4,17 \mathrm{bB}$ & $4,67 \mathrm{aB}$ & $7,23 \mathrm{cA}$ \\
\hline & $\mathrm{T} 5$ & $6,34 \mathrm{aB}$ & $6,43 \mathrm{aB}$ & $8,32 \mathrm{dA}$ \\
\hline \multirow{5}{*}{ Defeitos } & $\mathrm{T} 1$ & $3,90 \mathrm{cB}$ & $3,72 \mathrm{cB}$ & $5,59 \mathrm{aA}$ \\
\hline & $\mathrm{T} 2$ & $5,03 \mathrm{aA}$ & $4,32 \mathrm{bB}$ & $4,46 \mathrm{cB}$ \\
\hline & $\mathrm{T} 3$ & $4,61 \mathrm{bA}$ & $4,84 \mathrm{aA}$ & $4,94 \mathrm{bA}$ \\
\hline & $\mathrm{T} 4$ & $3,45 \mathrm{~dB}$ & $3,20 \mathrm{cB}$ & $6,62 \mathrm{aA}$ \\
\hline & $\mathrm{T} 5$ & $5,52 \mathrm{aA}$ & $3,95 \mathrm{bB}$ & $5,86 \mathrm{aA}$ \\
\hline \multirow{5}{*}{ Desidratação } & T1 & $0,40 \mathrm{cA}$ & $0,83 \mathrm{bcA}$ & $0,69 \mathrm{cA}$ \\
\hline & $\mathrm{T} 2$ & $0,80 \mathrm{bA}$ & $1,13 \mathrm{bA}$ & $1,15 \mathrm{bA}$ \\
\hline & $\mathrm{T} 3$ & $1,75 \mathrm{aA}$ & $2,34 \mathrm{aA}$ & $1,57 \mathrm{abA}$ \\
\hline & $\mathrm{T} 4$ & $1,59 \mathrm{aA}$ & $1,90 \mathrm{aA}$ & $1,95 \mathrm{aA}$ \\
\hline & $\mathrm{T} 5$ & $1,96 \mathrm{aB}$ & $2,10 \mathrm{aA}$ & $2,28 \mathrm{aA}$ \\
\hline \multirow{5}{*}{ Comercialização } & T1 & $3,90 \mathrm{cB}$ & $6,85 \mathrm{aA}$ & $6,74 \mathrm{aA}$ \\
\hline & $\mathrm{T} 2$ & $5,57 \mathrm{abB}$ & $5,47 \mathrm{cB}$ & $7,00 \mathrm{aA}$ \\
\hline & $\mathrm{T} 3$ & $2,60 \mathrm{~dB}$ & $4,81 \mathrm{cAB}$ & $4,97 \mathrm{bA}$ \\
\hline & $\mathrm{T} 4$ & $6,01 \mathrm{aA}$ & $6,52 \mathrm{abA}$ & $4,15 \mathrm{cB}$ \\
\hline & $\mathrm{T} 5$ & $5,10 \mathrm{bB}$ & $6,09 \mathrm{bA}$ & $4,64 \mathrm{bcB}$ \\
\hline
\end{tabular}

Médias seguidas da mesma letra maiúscula na linha ou mesma letra minúscula na coluna não diferem entre si, pelo teste de Tukey $(\mathrm{p}<0,05)$. T1 $1=30$ dias a $0^{\circ} \mathrm{C} ; \mathrm{T} 2=$ 10 dias a $0^{\circ} \mathrm{C}+5$ dias a $7^{\circ} \mathrm{C}+15$ dias a $0^{\circ} \mathrm{C} ; \mathrm{T} 3=10$ dias a ${ }^{\circ} \mathrm{C}+10$ dias a $7^{\circ} \mathrm{C}+10$ dias a $0^{\circ} \mathrm{C} ; \mathrm{T} 4=5$ dias a $0^{\circ} \mathrm{C}+5$ dias a $7^{\circ} \mathrm{C}+20$ dias a $0^{\circ} \mathrm{C}$; $\mathrm{T} 5=5$ dias a $0^{\circ} \mathrm{C}+$ 10 dias a $7^{\circ} \mathrm{C}+15$ dias a $0^{\circ} \mathrm{C}$ 
TABELA 5 - Avaliação sensorial das características de sabor (escala de $9 \mathrm{~cm}$ ) nas diferentes variações de temperatura e estádios de maturação de ameixas cv. Amarelinha após 30 dias de armazenamento e 3 de simulação de comercialização.

\begin{tabular}{|c|c|c|c|c|}
\hline \multirow{2}{*}{ Características de sabor } & \multirow{2}{*}{ Tratamentos } & \multicolumn{3}{|c|}{ Estádios de Maturação } \\
\hline & & Verde (M1) & Meio-maduro (M2) & Maduro (M3) \\
\hline \multirow{5}{*}{ Doçura } & $\mathrm{T} 1$ & $3,74 \mathrm{~dB}$ & $5,42 \mathrm{cA}$ & $5,85 \mathrm{cA}$ \\
\hline & $\mathrm{T} 2$ & $4,42 \mathrm{cC}$ & $6,42 \mathrm{bB}$ & $7,26 \mathrm{abA}$ \\
\hline & $\mathrm{T} 3$ & $6,33 \mathrm{aB}$ & $7,44 \mathrm{aA}$ & $7,62 \mathrm{aA}$ \\
\hline & $\mathrm{T} 4$ & $5,16 \mathrm{bC}$ & $5,90 \mathrm{cB}$ & $6,95 \mathrm{bA}$ \\
\hline & T5 & $5,60 \mathrm{bB}$ & 7,06 aA & $7,00 \mathrm{bA}$ \\
\hline \multirow{5}{*}{ Acidez } & $\mathrm{T} 1$ & $7,23 \mathrm{aA}$ & 7,56 aA & $4,67 \mathrm{aB}$ \\
\hline & $\mathrm{T} 2$ & $6,05 \mathrm{bB}$ & $6,61 \mathrm{bA}$ & $3,13 \mathrm{cC}$ \\
\hline & $\mathrm{T} 3$ & $2,48 \mathrm{cB}$ & $4,26 \mathrm{cA}$ & $2,20 \mathrm{~dB}$ \\
\hline & $\mathrm{T} 4$ & $4,28 \mathrm{dC}$ & $6,90 \mathrm{bA}$ & $4,37 \mathrm{aB}$ \\
\hline & T5 & $3,51 \mathrm{eB}$ & $4,64 \mathrm{cA}$ & $3,80 \mathrm{bB}$ \\
\hline \multirow{5}{*}{ Sabor } & T1 & $4,69 \mathrm{cC}$ & $7,07 \mathrm{bB}$ & $8,11 \mathrm{aA}$ \\
\hline & $\mathrm{T} 2$ & $5,44 \mathrm{bC}$ & 7,30 abAB & $7,62 \mathrm{abA}$ \\
\hline & T3 & $6,55 \mathrm{aB}$ & $7,64 \mathrm{aA}$ & $3,86 \mathrm{cC}$ \\
\hline & $\mathrm{T} 4$ & $3,97 \mathrm{dC}$ & $5,15 \mathrm{~dB}$ & 7,08 bA \\
\hline & T5 & $6,17 \mathrm{aA}$ & $6,30 \mathrm{cA}$ & $4,35 \mathrm{cB}$ \\
\hline \multirow{5}{*}{$\begin{array}{c}\text { Sabor } \\
\text { estranho }\end{array}$} & $\mathrm{T} 1$ & $3,87 \mathrm{aA}$ & $1,05 \mathrm{dC}$ & $1,57 \mathrm{~dB}$ \\
\hline & $\mathrm{T} 2$ & $3,31 \mathrm{bA}$ & $1,38 \mathrm{cdC}$ & $2,58 \mathrm{bcB}$ \\
\hline & $\mathrm{T} 3$ & $2,55 \mathrm{cB}$ & $2,67 \mathrm{aA}$ & $3,45 \mathrm{aA}$ \\
\hline & $\mathrm{T} 4$ & $3,66 \mathrm{abA}$ & $1,61 \mathrm{bcC}$ & $2,72 \mathrm{bcB}$ \\
\hline & T5 & $1,92 \mathrm{dBC}$ & $2,10 \mathrm{bB}$ & $3,10 \mathrm{abA}$ \\
\hline
\end{tabular}

Médias seguidas da mesma letra maiúscula na linha ou mesma letra minúscula na coluna não diferem entre si, pelo teste de Tukey (p<0,05). T1 $=30$ dias a

$0^{\circ} \mathrm{C} ; \mathrm{T} 2=10 \operatorname{dias}$ a $0^{\circ} \mathrm{C}+5 \operatorname{dias}$ a $7^{\circ} \mathrm{C}+15 \operatorname{dias}$ a $0^{\circ} \mathrm{C} ; \mathrm{T} 3=10 \operatorname{dias}$ a ${ }^{\circ} \mathrm{C}+10 \operatorname{dias}$ a $7^{\circ} \mathrm{C}+10$ dias a $0^{\circ} \mathrm{C} ; \mathrm{T} 4=5$ dias a $0^{\circ} \mathrm{C}+5$ dias a $7^{\circ} \mathrm{C}+20$ dias a $0^{\circ} \mathrm{C}$;

$\mathrm{T} 5=5$ dias a $0^{\circ} \mathrm{C}+10$ dias a $7^{\circ} \mathrm{C}+15$ dias a $0^{\circ} \mathrm{C}$.

Sua diminuição pode ser atribuída à perda excessiva de água dos tecidos, com a diminuição da pressão de turgescência que ocorre em situações de armazenamento em baixa umidade relativa do ar, com o desequilíbrio nutricional e também decorrente da ação enzimática sobre substâncias pécticas da parede celular (Crisosto et al., 1997).

Com relação à porcentagem de podridões, não ocorreram diferenças estatísticas na interação entre as variações de temperatura e estádios de maturação. $\mathrm{Na}$ avaliação isolada dos respectivos fatores, o valor médio da porcentagem de podridões foi de $8,66 \%$. Não houve diferença significativa devido à seleção e classificação uniformes das ameixas na instalação do experimento.

Segundo Kader (1986), a maioria dos microorganismos penetram por feridas causadas durante a colheita e pós-colheita ou distúrbios fisiológicos ocasionais, sendo a principal causa de deterioração, pois há poucos relatos em que patógenos podem infectar tecidos sadios.

$\mathrm{Na}$ porcentagem de escurecimento interno, não ocorreu diferença significativa entre as variações de temperatura. $\mathrm{O}$ escurecimento interno ocorreu somente no estádio de maturação M3 com incidência de 4,66\%. A incidência de escurecimento interno é influenciada pelo ponto de maturação na colheita de ameixas, sendo que quanto mais madura a fruta, mais suscetível a esse distúrbio (Taylor et al., 1995).

Também fatores de produção, como insuficiência de $\mathrm{Ca}, \mathrm{N}$ ou $\mathrm{K}$, solo muito ácido, falta de água antes da colheita, frutas colhidas verdes ou sobremaduras e demora em fazer o pré-resfriamento, são fatores agravantes no surgimento do escurecimento interno (Kluge et al., 1997).

Com relação às características de aparência, na avaliação da cor, observaram-se os menores valores nas frutas do tratamento T1 com cor amarelo-clara, indicando menor grau de maturação. Nos tratamentos com alternância de temperatura, principalmente no estádio de maturação M3, ocorreu o maior valor, indicando coloração amarelo intensa (Tabela 4). Isso ocorreu devido à influência das diferentes temperaturas de armazenamento e aos estádios de maturação nas características visuais das ameixas.

A evolução na coloração da fruta durante o armazenamento sofre aumento quando as frutas são transferidas do armazenamento a $0^{\circ} \mathrm{C}$ para temperaturas de $20^{\circ} \mathrm{C}$, devido ao desbloqueio na inibição da maturação provocado pelas baixas temperaturas (Lopez et al., 1998).
As ameixas em geral tiveram "regular" presença de defeitos, sendo que as frutas dos tratamentos T1 e T4 foram as que tiveram os menores índices. Apenas nos tratamentos T3, T4 e T5 as frutas tiveram "ligeira" desidratação.

A simulação da comercialização é uma característica importante na avaliação da qualidade das frutas; ela representa o somatório de todas as características de aparência, indicando a intenção de compra do consumidor.

Os maiores valores de aceitação foram obtidos no estádio de maturação M2, nas frutas dos tratamentos T1 e T4, indicando que a ameixa colhida no estádio de maturação meio-maduro e conservada em temperatura uniforme ou com menor variação durante o armazenamento, mantém a qualidade. Entretanto, no estádio de maturação M3, as ameixas dos tratamentos T1 e T2 obtiveram os maiores valores, enquanto com as frutas dos tratamentos T4 e T5 ocorreram os menores valores, indicando rejeição para compra, devido ao efeito prejudicial da oscilação da temperatura, resultando em frutas sobremaduras.

Durante o amadurecimento, as ameixas sofrem modificações físicas e químicas, tornando-as desejáveis para o consumo in natura. Dentre essas modificações, destacam-se o aumento da pigmentação da casca e da polpa, a diminuição da firmeza e da acidez, a solubilização das substâncias pécticas, o aumento do teor de açúcares. A menor doçura foi constatada no estádio de maturação M1, nas frutas dos tratamentos T1 e T2 com "ligeira a regular" doçura, indicando menor maturação. Já as frutas no estádio de maturação M3 tiveram "moderada" doçura, com exceção do tratamento T1, classificado como "regular" (Tabela 5). Os SSTs são compostos solúveis em água, entre os quais estão os açúcares existentes na fruta, sendo esta variável de grande importância na determinação do sabor e da qualidade da fruta.

Independentemente do estádio de maturação, no tratamento T1 ocorreram os maiores valores de acidez, sendo classificado como "moderadamente ácido" e demonstrando a importância da temperatura na manutenção da qualidade da fruta durante o armazenamento. Helbig (1998), trabalhando com ameixas cv. Wade, observou que, quando as frutas foram removidas da refrigeração e mantidas à temperatura ambiente, houve maior redução da acidez.

As frutas submetidas aos tratamentos T1, T2 e T4, no estádio de maturação M3, foram classificadas com intensidade moderada de 
TABELA 6 - Avaliação sensorial das características de textura (escala de $9 \mathrm{~cm}$ ) nas diferentes variações de temperatura e estádios de maturação de ameixas cv. Amarelinha após 30 dias de armazenamento e 3 de simulação de comercialização.

\begin{tabular}{|c|c|c|c|c|}
\hline \multirow{2}{*}{ Características de textura } & \multirow{2}{*}{ Tratamentos } & \multicolumn{3}{|c|}{ Estádios de Maturação } \\
\hline & & Verde (M1) & Meio-maduro (M2) & Maduro (M3) \\
\hline \multirow{5}{*}{ Firmeza } & T1 & $6,33 \mathrm{aA}$ & $5,79 \mathrm{aB}$ & $4,30 \mathrm{aC}$ \\
\hline & $\mathrm{T} 2$ & $3,89 \mathrm{cA}$ & $3,82 \mathrm{cAB}$ & $3,39 \mathrm{bB}$ \\
\hline & $\mathrm{T} 3$ & $2,23 \mathrm{dA}$ & $1,45 \mathrm{eB}$ & $1,12 \mathrm{cBC}$ \\
\hline & $\mathrm{T} 4$ & $5,94 \mathrm{abA}$ & $4,66 \mathrm{bB}$ & $3,89 \mathrm{abC}$ \\
\hline & T5 & $1,73 \mathrm{~dB}$ & $2,33 \mathrm{dA}$ & $0,85 \mathrm{cC}$ \\
\hline \multirow{5}{*}{ Suculência } & T1 & $5,17 \mathrm{dC}$ & $5,82 \mathrm{cB}$ & $6,42 \mathrm{cA}$ \\
\hline & $\mathrm{T} 2$ & $6,15 \mathrm{bB}$ & $6,49 \mathrm{bB}$ & $7,24 \mathrm{bA}$ \\
\hline & $\mathrm{T} 3$ & $6,60 \mathrm{abB}$ & $6,79 \mathrm{abB}$ & $7,93 \mathrm{aA}$ \\
\hline & $\mathrm{T} 4$ & $5,66 \mathrm{cB}$ & $5,25 \mathrm{~dB}$ & $6,34 \mathrm{cA}$ \\
\hline & $\mathrm{T} 5$ & $6,92 \mathrm{aB}$ & $7,09 \mathrm{aB}$ & $8,37 \mathrm{aA}$ \\
\hline \multirow{5}{*}{ Fibra } & T1 & $0,15 \mathrm{bA}$ & $0,31 \mathrm{aA}$ & $0,29 \mathrm{cA}$ \\
\hline & $\mathrm{T} 2$ & $0,21 \mathrm{bC}$ & $0,76 \mathrm{bcB}$ & $1,11 \mathrm{bA}$ \\
\hline & $\mathrm{T} 3$ & $0,17 \mathrm{bB}$ & $0,61 \mathrm{cAB}$ & $0,71 \mathrm{cA}$ \\
\hline & $\mathrm{T} 4$ & $0,52 \mathrm{aB}$ & $1,31 \mathrm{aA}$ & $1,69 \mathrm{aA}$ \\
\hline & $\mathrm{T} 5$ & $0,28 \mathrm{abB}$ & $0,99 \mathrm{abA}$ & $1,32 \mathrm{abA}$ \\
\hline \multirow{5}{*}{ Qualidade geral } & T1 & $5,88 \mathrm{cB}$ & $7,17 \mathrm{aA}$ & $7,31 \mathrm{aA}$ \\
\hline & $\mathrm{T} 2$ & $6,99 \mathrm{aA}$ & $6,89 \mathrm{abA}$ & $7,10 \mathrm{aA}$ \\
\hline & $\mathrm{T} 3$ & $6,44 \mathrm{bA}$ & $6,58 \mathrm{bA}$ & $3,73 \mathrm{~dB}$ \\
\hline & $\mathrm{T} 4$ & $5,49 \mathrm{cAB}$ & $5,98 \mathrm{cA}$ & $5,03 \mathrm{bB}$ \\
\hline & T5 & $4,98 \mathrm{cA}$ & $5,32 \mathrm{dA}$ & $4,27 \mathrm{cB}$ \\
\hline
\end{tabular}

Médias seguidas da mesma letra maiúscula na linha ou mesma letra minúscula na coluna não diferem entre si, pelo teste de $\mathrm{Tukey}(\mathrm{p}<0,05)$. $\mathrm{T} 1=30$ dias a $0^{\circ} \mathrm{C} ; \mathrm{T} 2=$ 10 dias a $0^{\circ} \mathrm{C}+5$ dias a $7^{\circ} \mathrm{C}+15$ dias a $0^{\circ} \mathrm{C} ; \mathrm{T} 3=10$ dias a ${ }^{\circ} \mathrm{C}+10$ dias a $7^{\circ} \mathrm{C}+10$ dias a $0{ }^{\circ} \mathrm{C} ; \mathrm{T} 4=5$ dias a $0^{\circ} \mathrm{C}+5$ dias a $7{ }^{\circ} \mathrm{C}+20$ dias a $0^{\circ} \mathrm{C} ; \mathrm{T} 5=5$ dias a $0^{\circ} \mathrm{C}+$ 10 dias a $7^{\circ} \mathrm{C}+15$ dias a $0^{\circ} \mathrm{C}$.

sabor, assim como nos tratamentos T3 e T5 no estádio de maturação M1. Nas ameixas no estádio de maturação M2, ocorreu maior intensidade de sabor característico; entre os tratamentos, sobressaíram-se os tratamentos T1, T2 e T3.

Os julgadores perceberam sabor ligeiramente estranho no estádio de maturação M1, indicando "ligeiro sabor à fruta verde" nos tratamentos T1, T2 e T4, enquanto no estádio de maturação M3 foi percebida alteração no sabor, sendo classificado como "ligeiro sabor de fruta sobremadura", os tratamentos T3 e T5, nos estádios de maturação M2 e M3, principalmente, neste último, confirmando os menores valores, quando avaliada a intensidade do sabor característico.

Segundo Torrellardona (1983), quando a colheita é realizada em estádios de maturação avançados, embora proporcione melhor evolução da coloração, limita o período de armazenamento pela maior desidratação, incidência de distúrbios fisiológicos, presença de sabores estranhos, podridões e rápida perda da firmeza da polpa.

Com relação às características de textura, as frutas dos tratamentos T1 e T4 tiveram maior consistência, entre os estádios de maturação, com exceção do tratamento T5, as frutas na maturação M1 tiveram maior firmeza.

As frutas dos tratamentos T3 e T5 tiveram menor firmeza, o que foi confirmado pelas alterações no sabor (sobremaduro), no estádio de maturação $M 3$. No tratamento T1, independentemente do estádio de maturação, as frutas tiveram firmeza de "regular a moderada". As frutas que tiveram menor firmeza foram as mais suculentas, principalmente no estádio de maturação M3, sendo classificadas como "moderadamente" suculentas. A presença de fibra foi percebida com pequena intensidade pelos julgadores (Tabela 6).

A maior qualidade geral foi atribuída às ameixas dos tratamentos T1 e T2 nos estádios de maturação M2 e M3, demonstrando, assim, a importância do armazenamento de ameixas sob baixas temperaturas de forma constante e do grau de maturação adequado na colheita para o armazenamento. De acordo com Handerburg et al. (1986), a temperatura é o fator individual do armazenamento mais importante na manutenção da qualidade, porque as taxas de muitos processos metabólicos são dependentes da temperatura. Segundo Rombaldi et al. (1999), colher as frutas em estádios menos avançados de maturação prolonga o período de conservação, porém a qualidade decresce de forma significativa.

\section{CONCLUSÕES}

1. Alternância de temperaturas durante o armazenamento refrigerado reduz o período de conservação de ameixas cv. Amarelinha.

2. Ameixas cv. Amarelinha colhidas no estádio de maturação meio-maduro podem ser armazenadas por período de até 30 dias a $0 \pm 0,5^{\circ} \mathrm{C}$ e UR de 90 a $95 \%$ com qualidade.

\section{REFERÊNCIAS}

BELING, R.R. Anuário brasileiro da fruticultura. Santa Cruz do Sul: GAZETA SANTA CRUZ, 2004. 136p.

CANTILLANO, R.F.F.; MALGARIM, M.B. Efeito do grau de maturação e período de armazenamento refrigerado na qualidade de ameixas cv. Amarelinha. In: CONGRESSO BRASILEIRO DE FRUTICULTURA, 17., 2002. Belém, 2002.

CHITARRA, M.I.F; CHITARRA, A.B. Pós-colheita de frutas e hortaliças: fisiologia e manuseio. Lavras: ESAL-FAEPE, 1990. 320p.

CRISOSTO, C.H., JOHNSON, R.S.; DEJONG, T. Orchard factors affecting postharvest stone fruit quality. HortScience, California, v.32, n.5, p.820-823, 1997.

GIRARDI,C.L.; ROMBALDI, C.V.; PARUSSOLO,A.; DANIELI, R. Manejo pós-colheita de pêssegos cultivar Chiripá. Bento Gonçalves, 2000. 36p. (Circular Técnica, 28)

HANDERBURG, R.E.; WATADA, A.E.; WANG, C.Y. The commercial storage of Fruits, vegetables, and florist, and mursery stoctks. Washington: USDA, 1986. 130p.

HELBIG, V.E. Maturação e tempo de armazenamento refrigerado na conservação de ameixas (prunus salicina, Lindl.) cvs. Pluma 7 e Wade. 1998. 63f. Dissertação (Mestrado em Fruticultura) - Faculdade de Agronomia Eliseu Maciel, Universidade Federal de Pelotas, Pelotas, 1998.

KADER, A.A. Biochemical and physiological basis for effects of controlled and modified atmospheres on fruits and vegetables. Food Techonology, Chicago, v.40, n.5, p.99-104, 1986.

KLUGE, R.A.; CANTILLANO, F.F.; Influência de ésteres sacarose no armazenamento refrigerado de ameixas "Amarelinha". Revista Brasileira de Fruticultura, Cruz das Almas, v.19, n.3, p.365-372, 1997. 
KLUGE, R.A.; NACHTIGAL, J.C.; FACHINELLO, J.C.; BILHALVA, A.J. Fisiologia e manejo pós-colheita de frutas de clima temperado. Pelotas: Editora Universitária UFPel, 1997. 163p.

KLUGE, R.A.; FILHO, J.A.S.; JACOMINO, A.P.; MARQUES, C. Embalagens plásticas para pêssegos "Flordaprince" refrigerados. Scientia Agrícola, Piracicaba, v.56, n.4, p.843-850, 1999.

LAWLESS H.T.; HAYMANN H. Sensory evaluation of food. New York: CHAPMAN \& HALL, 1998. 827p.

LOMBADI, R. Brasil aprimora produção de frutas cítricas. Revista Frutas \& Legumes: Ciclo de Produção, p. 8-14, 2003.

LÓPEZ, M.D.H.; MADRID, M.C.M.; BALLESTEROS, F.R.; MULA, M.S.; GARRIDO, D.V. Conservación frigorífica de melocotón parámetros de calidad. Fruticultura Profesional, Barcelona, n.93, p.55-59, 1998. MANZINO, M.B.de; SILVESTRI, M.P.de; REARTE, A.E. Identidad y calidad de los alimentos frutihortícolas industrializados. Mendoza: INTI, CITEF, 1987.p.4-5.

ROMBALDI, C.V.; ZIMMER, P.D.; SILVA, J.A; FERRI, V.C.; CHAVES, A.L. Inibição da síntese da ACC oxidase em maçãs armazenadas em atmosfera controlada. Revista Brasileira de Ciência e Tecnologia Agroindustrial, Campinas, v.18, p.27-33, 1999.

SOUTHY, M.; AUDERGON, J.M.; CHAMBROY, Y. Les critères de qualité. L'arboriculture frutière, Paris, n.430, p.18-24, 1990.

TAYLOR, M.A.; JACOBS, G.; RABE, E.; DODD, M.C. Effect of harvest maturity on pectic substances, internal conductivity, soluble solids and gel breakdown in cold stored 'Songold' plums. Postharvest Biology and Technology, Alexandria, v.5, p.285-294, 1995.

TORRELLARDONA, S.D. Frigoconservacion de la fruta. Barcelona: AEDOS, 1983.369p. 